
FACTORS IN PATIENTS WITH INFLAMMATORY RMDS

N. Marinez Alberola, C. Fernandez-Carballido, R. Martin Domenech, T. Pedraz Penalva, G. Albert Espi, F. Sivera Mascaró. Dpt Rheumatology, Hospital General Universitario Elda, Elda, Spain

Background: Patients with rheumatoid arthritis (RA), psoriatic arthritis (PSA) and spondyloarthritis $(\mathrm{SpA})$ have an increased risk of cardiovascular events when compared to the general population. This increase is probably due to both the deleterious effects of inflammation and the traditional cardio-vascular risk factors (CVRF).

Objectives: Analyse the differences by gender in the distribution of traditional CVRF in patients with chronic arthritis included in a screening program.

Methods: A program for the detection and management of traditional CVRF in patients with chronic arthritis was implemented following EULAR recommendations. Patients with RA, PsA and SpA followed-up at our department were included in this program. Patients underwent a baseline visit in a nurse-clinic where cardiovascular (CV) risk was assessed. Data on smoking status, diet, exercise, diagnosis of hypertension (HT), diabetes mellitus (DM), hypercholesterolemia ( $\mathrm{HCh}$ ) and prior $\mathrm{CV}$ events. The height and weight, the abdominal perimeter and the blood pressure of patients were measured. Results of a blood test previously ordered by the managing physician was recorded.

SCORE index was calculated as applied to Spanish population and then modified according to EULAR recommendations. Treatment targets (previously agreed upon by the department of rheumatology) were set; if pharmacological treatment was needed, patients were referred to their rheumatologist or GP.

Data are presented of all patients included in this screening program.

Results: The number of patients assessed at the nurse-led clinic for CVRF assessment and with data on gender, is 416 . In the table 1 we present the characteristics of these patients grouped by gender

Abstract AB0280 - Table 1

\begin{tabular}{lccc}
\hline & & $\begin{array}{c}\text { Women } \\
(\mathbf{n}=\mathbf{2 4 2})\end{array}$ & $\begin{array}{c}\text { Men } \\
(\mathbf{n}=174)\end{array}$ \\
\hline Age years, mean (SD) & RA & $59.6( \pm 11.9)$ & $56.7( \pm 12.8)$ \\
\hline Rheumatic disease & SpA & $179(73.9 \%)$ & $62(35.6 \%)$ \\
& PsA & $25(10.3 \%)$ & $70(40.2 \%)$ \\
Diabetes mellitus & Prior & $38(15.7 \%)$ & $42(24.2 \%)$ \\
& diagnosis & $25(10.3 \%)$ & $31(17.8 \%)$ \\
Hypertension & New diagnosis & $2(0.9 \%)$ & $4(2.8 \%)$ \\
& Poor control & $6(24 \%)$ & $10(32.2 \%)$ \\
& Prior & $93(38.4 \%)$ & $73(42 \%)$ \\
Hypercholesterolemia & diagnosis & $25(16.7 \%)$ & $22(21.7 \%)$ \\
& New diagnosis & $53(37 \%)$ & $33(45.2 \%)$ \\
& Poor control & $91(37.6 \%)$ & $69(39.6 \%)$ \\
Prior & diagnosis & $28(18.5 \%)$ & $23(21.9 \%)$ \\
Smoker & New diagnosis & $33(36.2 \%)$ & $16(23.2 \%)$ \\
Obesity & Poor control & $68(19.8 \%)$ & $60(24.5 \%)$ \\
Prior CV event & & $86(35.5 \%)$ & $63(36.2 \%)$ \\
\hline
\end{tabular}

Data expressed as $\mathrm{n}(\%)$ except where specified

* Poor control of hypercholesterolemia is defined as LDL over the target recommended by

European guidelines for each risk stratification.

Conclusions: In a similar manner as the general population, there is a greater number of $\mathrm{CV}$ events in men than in women. However, the gender-distribution of traditional CVRF is similar except for DM, more common in men.

Disclosure of Interest: None declared

DOI: 10.1136/annrheumdis-2018-eular.5722

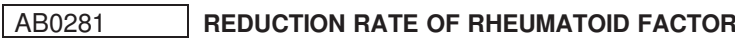 REFLECTS DISEASE ACTIVITY OF RHEUMATOID ARTHRITIS}

N. Okumura, T. Kawasaki, T. Yayama, K. Kumagai, S. Imai. Orthopaedic Surgery, Shiga University of Medical Science, Shiga, Japan

Background: Rheumatoid factor (RF) is involved in the pathology of rheumatoid arthritis (RA) and its titer varies during the course of treatment with biological or synthetic DMARD.

Objectives: In this study, we examined the relationship between RF change rate and disease activity.

Methods: We analysed 287 RA patients (mean age 62.3 years; mean disease duration 13.1 years) in our hospital between 2015 and 2017, who were able to confirm the RF, and 3 groups were classified according to the change rate of RF for 1 year (92 in decreasing less than $80 \%, 114$ in unchanged $80 \%$ or more, less than $120 \%$ and 81 in increasing $120 \%$ or more). We evaluated disease activity by simplified disease activity index(SDAl).

Results: The drugs used are: MTX usage rate $63.1 \%$, mean amount $3.81 \mathrm{mg}$ PSL usage rate $37.3 \%$, mean amount $1.47 \mathrm{mg}$, biological drugs usage rate $48.8 \%$. Disease activity change amount in 1 year (delta SDAl) was -0.88 (from 6.90 to 6.02 ). The median RF titer at baseline was 76 (27.5-178.5), the median RF change rate was $96 \%(71.5-125)$ and delta SDAI was significantly improved in the decreasing group $(-1.97,0.005,-0.04, p=0.0011)$. The swollen joint counts, tender joint counts, global assessment of evaluator and CRP were similarly improved significantly in this group.

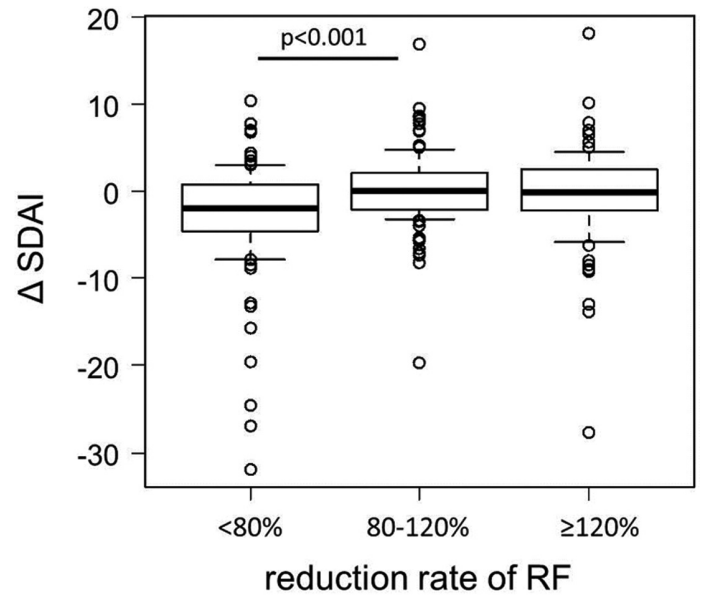

Conclusions: Although RF dose not decrease in all cases, it suggested that reduction rate of $\mathrm{RF}$ reflects disease activity.

Disclosure of Interest: None declared

DOI: 10.1136/annrheumdis-2018-eular.4496

\section{AB0282 ADJUSTING THE DOSE OF TOFACITINIB TO ACHIEVE OPTIMAL RESULTS IN THE MANAGEMENT OF PATIENTS WITH ACTIVE RHEUMATOID ARTHRITIS (RA) MAY OFFER MORE SUCCESSFUL RESULTS THAN UTILISING A STANDARD FIXED ONE DOSE APPROACH}

N. Gaylis ${ }^{1}$, J. Sagliani ${ }^{1}$, S. Needell ${ }^{2} .{ }^{1}$ Arthritis and Rheumatic Disease Specialties, Aventura; ${ }^{2}$ Boca Radiology, Boca Raton, USA

Background: We have previously reported results of patients with active RA who had been unresponsive to tofacitinib at $5 \mathrm{mg}$ bid but who had demonstrated significant response after dose escalation to $10 \mathrm{mg}$ bid. ${ }^{12}$ This extension trial was performed to see if 9 patients who had failed to reach treatment target on $5 \mathrm{mg}$ bid but then responded to $10 \mathrm{mg}$ bid of tofacitinib would maintain their clinical target if the dose was reduced down to $5 \mathrm{mg}$ bid. Furthermore, if the patients could not maintain their clinical response on the lower dose, we explored whether increasing the dose of tofacitinib up to $10 \mathrm{mg}$ bid could again result in a target response. Objectives: The objectives were as follows: to explore the response of patients who achieved a treatment target when taking $10 \mathrm{mg}$ bid of tofacitinib and then reduced the dose down to $5 \mathrm{mg}$ bid; to report the results of the patients who could not maintain the target response at $5 \mathrm{mg}$ bid and then increased the dose back up to $10 \mathrm{mg}$ bid;and to identify if there was any separation between the clinical and structural findings at $5 \mathrm{mg}$ bid vs $10 \mathrm{mg}$ bid.

Methods: Nine RA patients who were unresponsive to treatment with tofacitinib at a dose of $5 \mathrm{mg}$ bid plus MTX (10-25 mg weekly) were dose escalated to $10 \mathrm{mg}$ bid and reached low disease activity (LDA) or remission at the increased dose. These patients were maintained on $10 \mathrm{mg}$ bid of tofacitinib for 6 months and sustained a clinical target of LDA or remission. After 6 months, the dose of tofacitinib was reduced back to $5 \mathrm{mg}$ bid which had previously not been an effective dose. The clinical response was measured by the Clinical Disease Activity Index (CDAl) and the structural response was measured by an MRI of the index hand/wrist and blindly read by a musculoskeletal radiologist using a modified OMERACT-RAMRIS score. If the patients could not maintain their positive clinical response for 3 months the dose of tofacitinib was escalated back up to $10 \mathrm{mg}$ bid.

Results: Of the 9 enrolled patients, 6 patients maintained LDA or Remission over the next 6 months once the dose of tofacitinib was reduced back down to $5 \mathrm{mg}$ bid. Three ${ }^{3}$ patients were unable to maintain their treatment target at the reduced dose and were dose escalated back up to $10 \mathrm{mg}$ bid at which time they achieved the treatment target.(See table 1) The MRI findings showed no difference in structure at either dose and do not appear to demonstrate a relationship to the clinical findings. There were no clinically significant adverse events in either group. 